\title{
Reduced stocking density mitigates the negative effects of regrouping in dairy cattle
}

\author{
A. Talebi, M. A. G. von Keyserlingk, E. Telezhenko, and D. M. Weary ${ }^{1}$ \\ Animal Welfare Program, University of British Columbia, 2357 Main Mall, Vancouver V6T 1Z4, BC, Canada
}

\begin{abstract}
In freestall systems, cows are frequently moved among pens and regrouped. This practice involves mixing unfamiliar cows, and can result in changes in stocking density after regrouping. Both regrouping and changes in stocking density can affect cow welfare, but no study to date has assessed the combined effects. The aim of this study was to test if reductions in stocking density can mitigate the responses to regrouping. By manipulating group size (6 vs. 12 cows) and pen size (12 vs. 24 stalls), 3 different stocking densities were created $(25,50$, and 100\%). Four groups of Holstein cows were regrouped weekly for $4 \mathrm{wk}$ and the stocking density changed at regrouping. The change in density varied as follows: a decrease by a factor of 4 (100 to $25 \%$ ), a decrease by a factor of 2 (100 to $50 \%$ or 50 to $25 \%$ ), no change (50 to $50 \%$ ), an increase by a factor of 2 (25 to $50 \%$ or 50 to $100 \%$ ), and an increase by a factor of 4 (25 to 100\%). Displacements at the feeding area, feeding time, and lying time were scored. The daily means for each group were used to calculate the differences in responses from $1 \mathrm{~d}$ before to $1 \mathrm{~d}$ after each regrouping. The number of displacements at the feed bunk decreased and lying time increased when stocking density decreased at regrouping. In conclusion, increases in competitive behavior and the associated decrease in lying times can be mitigated by reducing stocking density when regrouping dairy cows.
\end{abstract}

Key words: cow, housing, group size, pen size, feeding behavior

\section{INTRODUCTION}

In freestall systems, cows are often required to compete for access to resources, including feed and lying stalls (Val-Laillet et al., 2008). Regrouping and changing stocking density are 2 management practices that increase this competition (e.g., Miller and Wood-Gush,

Received April 12, 2013.

Accepted November 11, 2013.

${ }^{1}$ Corresponding author: danweary@mail.ubc.ca
1991; Hasegawa et al., 1997; Olofsson, 1999), potentially compromising cow welfare.

On commercial farms, cows are frequently moved to form groups similar in age, stage of lactation, milk production, health, and reproductive status (Grant and Albright, 2001; Bøe and Færevik, 2003), such that cows may experience 4 to 5 regrouping events during a single lactation (Grant and Albright, 2001). Research on the effects of regrouping in dairy cows is minimal and some of this work suffers from poor replication and limited sample size (e.g., Brakel and Leis, 1976; Hasegawa et al., 1997). Previous work suggests that mixing cows with unfamiliar animals that already have an established social order destabilizes the social dynamic within the group (Bøe and Færevik, 2003). After regrouping, dairy cows increase physical competition (e.g., Kondo and Hurnik, 1990; Bøe and Færevik, 2003) and this increased competition can result in reduced lying and feeding, further compromising welfare (e.g., Phillips and Rind, 2001; von Keyserlingk et al., 2008; Schirmann et al., 2011).

Regrouping may also affect the stocking density within the pen, which also affects competitive encounters among cows (Bøe and Færevik, 2003). Increasing stocking density can increase competition over feed and decrease the time cows spend feeding (Huzzey et al., 2006) and lying down (e.g., Cook et al., 2005; Telezhenko et al., 2012).

Separate lines of experimental work suggest that both regrouping and increased stocking density have negative effects on cows, but to date, no study has assessed the combined effects despite these events occurring simultaneously on many commercial farms. The aim of this study was to evaluate competitive, feeding, and lying behaviors of dairy cows following regrouping into pens with varying densities. We predicted that competition would decrease when density decreased at regrouping, with positive effects on feeding and lying time.

\section{MATERIALS AND METHODS}

This experiment was performed at the University of British Columbia's Dairy Education and Research 
Centre (Vancouver, BC, Canada) and used 72 lactating Holstein cows. Experimental cows were selected randomly from mid- and late-lactation cows in the herd with average parity of $2.6 \pm 1.8$ (mean $\pm \mathrm{SD}$; range 1 to 9 ), average DIM of $204 \pm 47$ (range 125 to 296), and average milk production of $19 \pm 3.5 \mathrm{~kg}$ (range 12 to $29.5 \mathrm{~kg}$ ). These are the same cows as described in Telezhenko et al. (2012), but the present study addresses a different question and reports different data, specifically focusing on responses to regrouping. Before the study, cows were managed as part of our 240-cow milking herd. The experiment used cows from different pens within the barn, but it is likely that many of the cows had some social experience with one another before the experiment began. Cows were managed in compliance with the guidelines set by the Canadian Council on Animal Care (CCAC, 2009).

Cows were housed in either small pens $(7.2 \times 13.5$ $\mathrm{m})$ with 12 stalls or large pens $(14.4 \times 13.5 \mathrm{~m})$ with 24 stalls, configured in 3 rows of 4 stalls (small pen) or 3 rows of 8 stalls (large pen). In each pen, 2 rows of freestalls faced one another and were open at the front (head to head), with a bed length of $2.4 \mathrm{~m}$. The third row of freestalls faced a chasing alley (separated by a low concrete wall); these stalls were $0.3 \mathrm{~m}$ longer. Stalls were bedded with $0.4 \mathrm{~m}$ of sand, measured $1.2 \mathrm{~m}$ wide center to center, with a neck rail $1.14 \mathrm{~m}$ above the stall surface. Cows accessed the feed bunk via a pendulous feed rail. The alley closest to the feed bunk was $3.6 \mathrm{~m}$ wide and the alley between the freestall rows was $2.5 \mathrm{~m}$ wide. Flooring throughout the pen (including the crossover alley) was grooved concrete. Alleys were cleaned 6 times/d with automatic scrapers and the crossover alley manually scraped twice per day.

Cows were fed a TMR consisting of $27.2 \%$ corn silage, $16.7 \%$ grass silage, $8.5 \%$ alfalfa hay, and $47.6 \%$ concentrate and mineral mix on a DM basis. Major ingredients of concentrate include fine ground barley, rolled barley, rolled corn, distillers corn wheat blend, canola meal, and soybean meal. Feed was formulated based on NRC (2001) recommendations. Water was available ad libitum. Milking took place twice per day at 0500 to $0600 \mathrm{~h}$ and 1500 to $1600 \mathrm{~h}$. Fresh feed was delivered twice daily during each milking so that cows had access to the fresh feed when they returned to their pens.

\section{Experimental Design}

Two replicates were conducted, each lasting $5 \mathrm{wk}$; the first replicate took place in October and November 2009 and the second in April and May 2010. In each replicate, 24 cows were randomly selected as focal cows and 12 others as nonfocal cows. Focal cows were ran- domly assigned to 4 groups of 6 cows each; nonfocal cows were assigned to 2 constant groups of "filler cows."

Stocking density in this study relates specifically to the number of stalls per cow, as feeding space was held constant across treatments (at $0.6 \mathrm{~m} / \mathrm{cow}$ ). Stocking density related to group size (6 vs. 12 cows) and pen size (small vs. large) and varied from 4 stalls/cow (25\%) to 2 stalls/cow (50\%) to 1 stall/cow (100\%). Gates were moved to form small and large pens and 6 nonfocal cows used to change the group size. Focal cows remained in the same pen throughout the experiment but nonfocal cows were moved upon return from morning milking and grouped with focal cows to form the large groups (12 cows). Groups remained in the same pen for $7 \mathrm{~d}$. Experimental pens were separated by nonexperimental pens that were stocked at $100 \%$ density.

At each regrouping, pen size, group size, or both were changed (Table 1 and Figure 1). A total of 8 different types of change were tested. Each group was tested with 4 changes, such that within each replicate of 4 groups, each type of change was tested twice.

\section{Behaviors}

Pens were monitored $24 \mathrm{~h} / \mathrm{d}$ using 16 digital cameras (WV-BP330; Panasonic Corp., Osaka, Japan). Small and large pens had 2 and 4 cameras, respectively. Videos were recorded using a digital video surveillance system (GeoVision, version 8.3; GeoVision Inc., Corona, CA). A red light $(100 \mathrm{~W})$ was placed beside each camera to improve the video quality at night. Focal cows were marked with individually distinct symbols using hair dye on the back and sides to aid in identification. Feeding and lying time were scored using scan sampling every $5 \mathrm{~min}$ from $1 \mathrm{~d}$ before to $1 \mathrm{~d}$ after regrouping. Cows were considered to be feeding when the neck collar was beyond the feed rail.

Videos were watched continuously for $3 \mathrm{~h}$ following afternoon delivery of fresh feed (from approximately 1530 to $1830 \mathrm{~h}$ ) $1 \mathrm{~d}$ before and $1 \mathrm{~d}$ after regrouping,

Table 1. At regrouping, cows were moved to pens that were formed by changing group size (either 6 or 12 cows) and pen size [either large (24 stalls) or small (12 stalls)], resulting in different stocking densities (no. of stalls/cow)

\begin{tabular}{llll}
\hline $\begin{array}{l}\text { Treatment } \\
\text { no. }\end{array}$ & $\begin{array}{l}\text { Change in } \\
\text { group size }\end{array}$ & $\begin{array}{l}\text { Change in } \\
\text { pen size }\end{array}$ & $\begin{array}{l}\text { Change in } \\
\text { density }\end{array}$ \\
\hline 1 & 6 to 12 & Large to small & 4 to 1 \\
2 & 12 to 6 & Small to small & 1 to 2 \\
3 & 6 to 12 & Small to large & 2 to 2 \\
4 & 12 to 6 & Large to large & 2 to 4 \\
5 & 6 to 12 & Large to large & 4 to 2 \\
6 & 12 to 6 & Large to small & 2 to 2 \\
7 & 6 to 12 & Small to small & 2 to 1 \\
8 & 12 to 6 & Small to large & 1 to 4 \\
\hline
\end{tabular}


1360

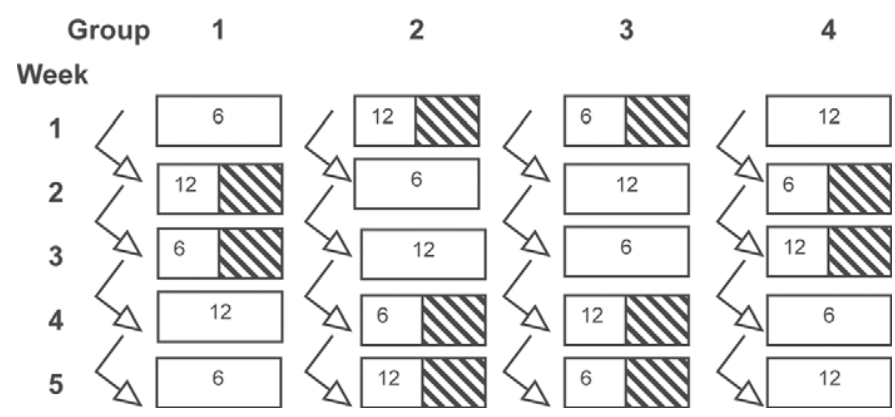

Figure 1. The time course of changes in pen size and group size used to create different densities in each replicate. Large white rectangles show the large pens and small white rectangles show the small pens: the hashed area illustrates the part of the pen that was not accessible. Numbers within boxes show the number of cows in each pen. Arrows show the order in which each group was exposed to treatments.

with each displacement recorded using Observer software (version 5.0; Noldus Information Technology BV, Wageningen, the Netherlands). A displacement was recorded when one cow came into physical contact with another cow that was feeding, resulting in the feeding cow withdrawing her head from the feed bunk.

\section{Data Analysis}

Cows were treated as observational unit and pens as experimental unit. Interobserver reliability was tested between the 2 trained observers (15 observations for each of feeding, lying, and displacement variables) using regression and the results showed strong agreement $\left(\mathrm{R}^{2}>0.98\right)$.

The UNIVARIATE procedure in SAS (version 9.2; SAS Institute Inc., Cary, NC) was used to evaluate distributions for normality and the presence of outliers. An observation was considered as an extreme outlier when it was more than 3 times outside the interquartile range; 3 observations for the displacements and 1 for the lying time were identified as outliers and excluded. One cow was in estrus during observations and was excluded from all analyses.

For all variables, data were summarized to create 1 observation per day before, and $1 \mathrm{~d}$ after each regrouping, for each group. The means were used to calculate the difference in response to regrouping. This difference contributed to 1 observation for each group and treatment, providing a total of 32 observations. Response measures were analyzed with PROC MIXED of SAS (version 9.3; SAS Institute Inc.). The effect of treatment ( $7 \mathrm{df})$ was tested in a model that included week $(1 \mathrm{df})$ specified as a repeated measure and group specified as subject, using an autoregressive covariance structure.

Specified contrasts were used to test the effects of changes in pen size (i.e., treatments that involved moving cows from a small pen to a large pen and vice versa; treatments 3 and 8 vs. 1 and $6 ; 1 \mathrm{df}$ ) and group size (i.e., treatments that involved moving cows from a small group to a large group and vice versa; treatments $1,3,5$, and 7 vs. $2,4,6$, and $8 ; 1 \mathrm{df}$ ), irrespective of density. The combined changes in pen size and group size resulted in changes in stocking density ( $1 \mathrm{df})$, varying from a 4-fold increase (treatment 8), to a doubling (treatments 2 and 4), to no change (treatments 3 and 6 ), to a halving (treatments 5 and 7 ), and to a quartering (treatment 1 ). We also tested the combined effect of changes in pen and group size in the treatments that did not affect density (i.e., treatments 3 and 6); these equidensity treatments included changing from a large pen and group to small pen and group and vice versa; $1 \mathrm{df})$.

\section{RESULTS}

\section{Competitive Behavior}

On the day before regrouping, the focal cows engaged in displacements at the feeding area on average $( \pm \mathrm{SD})$ $6.2 \pm 4.5$ times/cow during the $3 \mathrm{~h}$ after delivery of fresh feed. After regrouping, the number of displacements changed depending upon the change in stocking density (Figure 2). For instance, the number of displacements decreased by approximately 1.2 events/cow per $3 \mathrm{~h}$ when the stocking density decreased on the day after regrouping, but when the stocking density increased, the number of displacements increased by approximately 1.5 events/cow per $3 \mathrm{~h}$.

This effect of density was associated with changes in group size; the number of displacements increased when group size increased and decreased when group

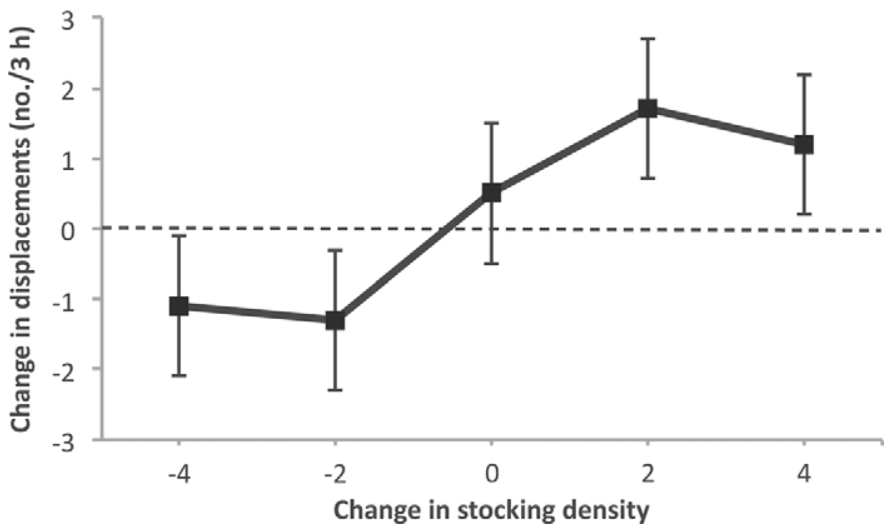

Figure 2. Means $( \pm \mathrm{SE})$ differences in the number of displacements at the feed bunk from $1 \mathrm{~d}$ before to $1 \mathrm{~d}$ after imposing changes in stocking density. Density is shown on the $\mathrm{x}$-axis and varied as follows: decreased density by a factor of 4 and by a factor of 2 , no change in density, and increased density by a factor 2 and by a factor 4 . 
size decreased, but no effect of changes in pen size was observed (Table 2). When pen and group size changed without a change in density (i.e., equidensity changes), no change in competitive behavior was observed.

\section{Lying Behavior}

The day before regrouping, focal cows averaged $( \pm \mathrm{SD}) 14.4 \pm 1.8 \mathrm{~h} / \mathrm{d}$ lying down. Changes in this behavior after regrouping varied primarily in relation to changes in pen size. For example, when pen size increased, lying time increased by $0.29 \mathrm{~h} / \mathrm{d}$ and when pen size was decreased, lying time decreased by 0.31 $\mathrm{h} / \mathrm{d}$. Although the effect of density was significant, we suggest that this effect was largely driven by changes in pen size. Indeed, when pen and group size were changed simultaneously without changing density (i.e., in the equidensity treatments), increased pen size resulted in an increase in lying time and decreased pen size resulted in decreased lying time.

\section{Feeding Behavior}

On the day before regrouping, focal cows averaged $( \pm \mathrm{SD}) 5.2 \pm 1.0 \mathrm{~h} / \mathrm{d}$ at the feeder. No changes in this behavior were observed in relation to changes in pen size, group size, or stocking density at regrouping.

\section{DISCUSSION}

On dairy farms, stocking density often changes at the time of regrouping. Although some work has studied the effect of changes in stocking density on the welfare of dairy cows, and other work has investigated the effect of regrouping, to date, no studies have tested the effects of changes in density when cows are regrouped. The current study addresses this gap by showing that regrouping and increased stocking density can both have negative effects on the cow.

Group size and pen size both affect stocking density. Because of the interrelatedness of stocking density, group size, and pen size, separating the effects of each of these 3 factors is a challenge (Leone and Estevez, 2008). Our experimental design enabled us to test the effects of group size and pen size on the outcome variables.

\section{Competitive Behavior}

On the day before regrouping, focal cows were involved in approximately 6 displacements during the 3 $\mathrm{h}$ after delivery of fresh feed. This value is similar to the 5.7 displacements $/ 3 \mathrm{~h}$ reported by Schirmann et al. (2011). Results of the current study indicate that

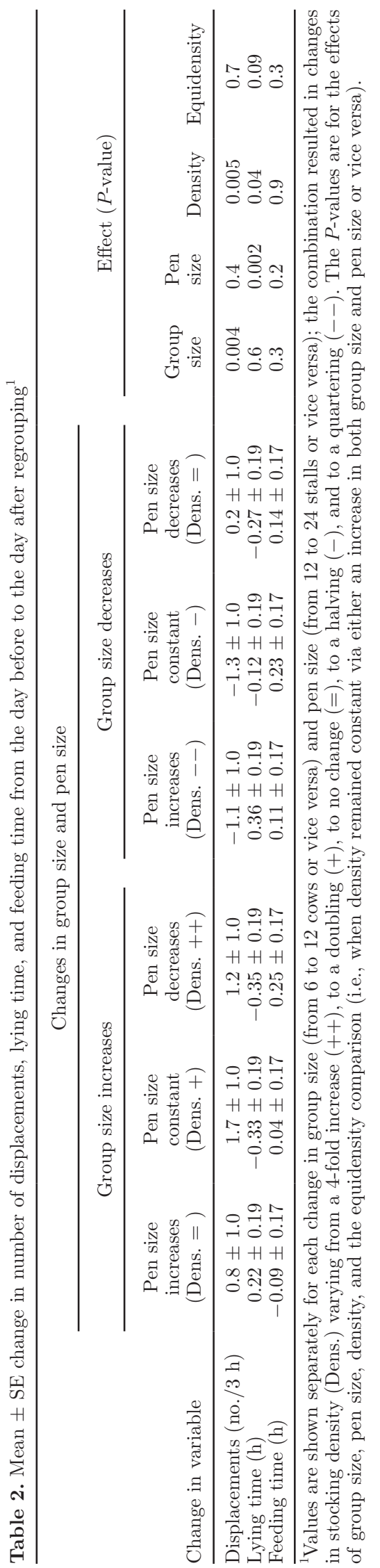

Journal of Dairy Science Vol. 97 No. 3, 2014 
aggressive competition over resources increases after regrouping and supports findings of previous studies (e.g., Brakel and Leis, 1976; Hasegawa et al., 1997; von Keyserlingk et al., 2008). Regrouping disturbs social behavior in other farm animals, including pigs (e.g., McGlone and Curtis, 1985; Stookey and Gonyou, 1994) and laying hens (e.g., Abeyesinghe et al., 2009). It is well known that when stocking density increases, competition among cows at the feeding area also increases (e.g., Olofsson, 1999; DeVries and von Keyserlingk, 2006). Similar studies in calves (Kondo et al., 1989) and transition cows (e.g., Proudfoot et al., 2009) also show that increasing stocking density increased aggressive competition over feed. Results of our study agree with these previous studies showing that increased stocking density at regrouping increased the number of displacements at the feeding area during the $3 \mathrm{~h}$ following fresh feed delivery when cows were highly motivated to feed (e.g., DeVries and von Keyserlingk, 2005).

In the current study, we varied stocking density within the pen, but not at the feed bunk. We expect that the effects of stocking density on displacements reported here would have been greater had we also manipulated density at the feed bunk where these displacements were recorded. That increased density at the stall also affects competitive behavior at the feed barrier suggests that overstocking for one resource can have important implications on competitive behavior among cows for other resources within the pen.

\section{Lying Behavior}

On the day before regrouping, cows in the current study spent approximately $14 \mathrm{~h} / \mathrm{d}$ lying down; this value is within the range found by other experimental studies on late-lactation cows (e.g., Drissler et al., 2005) but higher than lying times of cows in peak lactation on commercial farms (von Keyserlingk et al., 2012). Results of the few previous studies on this topic suggest that cows spend less time lying down after regrouping (e.g., Hasegawa et al., 1997; Phillips and Rind, 2001; von Keyserlingk et al., 2008) and when stocked at higher densities (e.g., Fregonesi et al., 2007; Hill et al., 2009; Telezhenko et al., 2012). Our results are consistent with these previous studies, and also indicate that changes in lying behavior due to regrouping are dependent upon changes in stocking density. The effect of changes in stocking density on lying behavior appeared to be driven by the changes in pen size; when cows were regrouped into a smaller pen, lying time decreased, and regrouping cows into a larger pen allowed for increased lying times.

A companion study (Telezhenko et al., 2012) explored the effects of the physical dimensions of the pen and group size and stocking density on cow activity. Those authors reported that cows housed in large pens moved more compared with when they were housed in small pens, regardless of group size. Those results indicate that pen size plays a major role in determining how much cows move. The only related study, which was done on pigs (Hyun et al., 1998), reported that grouping and reducing pen size reduced growth rate and changed feeding behavior.

\section{Feeding Behavior}

On the day before regrouping, focal cows spent approximately $5 \mathrm{~h} / \mathrm{d}$ at the feed bunk. This result is similar to previous studies indicating that dairy cows spend an average of 3 to $5 \mathrm{~h} / \mathrm{d}$ feeding (e.g., DeVries and von Keyserlingk, 2006; Huzzey et al., 2006). In the current study, stocking density at the feeder was held constant across treatments, explaining the lack of effect of treatment on changes in feeding time.

\section{CONCLUSIONS}

Changes in stocking density at regrouping affect competition and lying behavior. The current study is the first to show that the effects of regrouping are aggravated by concurrent increases in density, as well as related changes in group and pen size. Our findings indicate that by decreasing stocking density at regrouping, aggressive competition over feed decreases, reducing the effect of regrouping on lying time. We suggest that producers can use changes in stocking density, pen size, and group size to alleviate the negative effects of regrouping on dairy cows. We caution readers that the large pen in the current study was still small relative to pen dimensions used on many large commercial farms; future work should assess the effects of larger pen and group sizes often found on dairy farms.

\section{ACKNOWLEDGMENTS}

We thank faculty, staff, and students at The University of British Columbia's Animal Welfare Program and the University's Dairy Education and Research Centre (Vancouver, BC, Canada). The Animal Welfare Program is funded by Canada's Natural Sciences and Engineering Research Council (NSERC) Industrial Research Chair Program (Ottawa, ON, Canada), with industry contributions from the Dairy Farmers of Canada (Ottawa, ON, Canada), Westgen Endowment Fund (Milner, BC, Canada), Zoetis (Kirkland, QC, Canada), BC Cattle Industry Development Fund (Kamloops, BC, Canada), the BC Dairy Association (Burnaby, BC, Canada), and Alberta Milk (Edmonton, AB, Canada). 


\section{REFERENCES}

Abeyesinghe, S. M., M. A. McLeman, R. C. Owen, C. E. McMahon, and C. M. Wathes. 2009. Investigating social discrimination of group members by laying hens. Behav. Processes 81:1-13.

Bøe, K. E., and G. Færevik. 2003. Grouping and social preferences in calves, heifers and cows. Appl. Anim. Behav. Sci. 80:175-190.

Brakel, W. J., and R. A. Leis. 1976. Impact of social disorganization on behavior, milk yield, and body weight of dairy cows. J. Dairy Sci. 59:716-721.

CCAC (Canadian Council on Animal Care). 2009. Guide to the Care and Use of Experimental Animals. Vol. 1. E. D. Olfert, B. M. Cross, and A. A. McWilliam, ed. Canadian Council on Animal Care, Ottawa, ON, Canada

Cook, N. B., T. B. Bennett, and K. V. Nordlund. 2005. Monitoring indices of cow comfort in free-stall-housed dairy herds. J. Dairy Sci. 88:3876-3885

DeVries, T. J., and M. A. G. von Keyserlingk. 2005. Time of feed delivery affects the feeding and lying patterns of dairy cows. J. Dairy Sci. 88:625-631.

DeVries, T. J., and M. A. G. von Keyserlingk. 2006. Feed stalls affect the social and feeding behavior of lactating dairy cows. J. Dairy Sci. 89:3522-3531.

Drissler, M., M. Gaworski, C. B. Tucker, and D. M. Weary. 2005 Freestall maintenance: Effects on lying behavior of dairy cattle. J. Dairy Sci. 88:2381-2387.

Fregonesi, J. A., C. B. Tucker, and D. M. Weary. 2007. Overstocking reduces lying time in dairy cows. J. Dairy Sci. 90:3349-3354.

Grant, R. J., and J. L. Albright. 2001. Effect of animal grouping on feeding behavior and intake of dairy cattle. J. Dairy Sci. 84(E. Suppl.):E156-E163.

Hasegawa, N., A. Nishiwaki, K. Sugawara, and I. Ito. 1997. The effects of social exchange between two groups of lactating primiparous heifers on milk production, dominance order, behavior and adrenocortical response. Appl. Anim. Behav. Sci. 51:15-27.

Hill, C. T., P. D. Krawczel, H. M. Dann, C. S. Ballard, R. C. Hovey, W. A. Falls, and R. J. Grant. 2009. Effect of stocking density on the short-term behavioral responses of dairy cows. Appl. Anim. Behav. Sci. 117:144-149.

Huzzey, J. M., T. J. DeVries, P. Valois, and M. A. G. von Keyserlingk. 2006. Stocking density and feed barrier design affect the feeding and social behavior of dairy cattle. J. Dairy Sci. 89:126-133.

Hyun, Y., M. Ellis, and R. W. Johnson. 1998. Effects of feeder type, space allowance, and mixing on the growth performance and feed intake pattern of growing pigs. J. Anim. Sci. 76:2771-2778.
Kondo, S., and J. F. Hurnik. 1990. Stabilization of social hierarchy in dairy cows. Appl. Anim. Behav. Sci. 27:287-297.

Kondo, S., J. Sekine, M. Okubo, and Y. Asahida. 1989. The effect of group size and space allowance on the agonistic and spacing behavior of cattle. Appl. Anim. Behav. Sci. 24:127-135.

Leone, E. H., and I. Estevez. 2008. Use of space in the domestic fowl: Separating the effects of enclosure size, group size and density. Anim. Behav. 76:1673-1682.

McGlone, J. J., and S. E. Curtis. 1985. Behavior and performance of weanling pigs in pens equipped with hide areas. J. Anim. Sci 60:20-24.

Miller, K., and D. G. M. Wood-Gush. 1991. Some effects of housing on the social behaviour of dairy cows. Anim. Prod. 53:271-278.

NRC. 2001. Nutrient Requirements of Dairy Cattle. 7th rev. ed. National Academy Press, Washington, DC.

Olofsson, J. 1999. Competition for total mixed diets fed for ad libitum intake using one or four cows per feeding station. J. Dairy Sci 82:69-79.

Phillips, C. J. C., and M. I. Rind. 2001. The effects on production and behavior of mixing uniparous and multiparous cows. J. Dairy Sci. 84:2424-2429.

Proudfoot, K. L., D. M. Veira, D. M. Weary, and M. A. G. von Keyserlingk. 2009. Competition at the feed bunk changes the feeding, standing and social behavior of transition dairy cows. J. Dairy Sci. 92:3116-3123.

Schirmann, K., N. Chapinal, D. M. Weary, W. Heuwieser, and M. A. G. von Keyserlingk. 2011. Short-term effects of regrouping on behavior of prepartum dairy cows. J. Dairy Sci. 94:2312-2319.

Stookey, J. M., and H. W. Gonyou. 1994. The effects of regrouping on behavioral and production parameters in finishing swine. J. Anim. Sci. 72:2804-2811.

Telezhenko, E., M. A. G. von Keyserlingk, A. Talebi, and D. M. Weary. 2012. Effect of pen size, group size, and stocking density on activity in freestall-housed dairy cows. J. Dairy Sci. 95:3064-3069.

Val-Laillet, D., D. M. Veira, and M. A. G. von Keyserlingk. 2008. Short communication: Dominance in free-stall-housed dairy cattle is dependent upon recourse. J. Dairy Sci. 91:3922-3926.

von Keyserlingk, M. A. G., A. Barrientos, K. Ito, E. Galo, and D. M. Weary. 2012. Benchmarking cow comfort on North American freestall dairies: Lameness, leg injuries, lying time, facility design, and management for high-producing Holstein dairy cows. J. Dairy Sci. 95:7399-7408.

von Keyserlingk, M. A. G., D. Olenick, and D. M. Weary. 2008. Acute behavioral effects of regrouping dairy cows. J. Dairy Sci. 91:10111016. 